\title{
Evaluation of Foraminal Enlargement with Thermally Treated Nickel-Titanium Systems
}

\author{
Mônica M Bezerra ${ }^{1}$, Victor P Feitosa ${ }^{2}$, Flávia D Vivacqua ${ }^{3}$, Bruno $C$ de Vasconcelos ${ }^{4}$, Nilton Vivacqua-Gomes ${ }^{5}$
}

\begin{abstract}
Aim and objective: To evaluate morphologic changes in the main foramen after enlargement with four different systems. Materials and methods: One hundred and twenty canals (buccal of maxillary molars and mesial of mandibular molars) with patency and apical foramen $\leq 200 \mu \mathrm{m}$ were included. These apical foramina were photographed and then randomly divided into four experimental groups, according to the ProDesign Logic (PDL), ProDesign R (PDR), twisted file adaptive (TFA), and WaveOne Gold (WOG) systems, all of which were composed of three sequential instruments (Glidepath, \#25 and \#35). Root canals were prepared $1 \mathrm{~mm}$ beyond the main foramen ( $n=30$ ). The specimens were photographed again to capture intermediate (\#25) and final enlargement (\#35) images. These were analyzed using an image software that allowed comparison of the enlarged area and shape of the main foramen.

Results: In the Intragroup comparison, the Friedman's test showed a statistical difference between each phase of foramen enlargement $(p<0.05)$. In the intergroup comparison, the percentage of foramen enlargement showed statistically significant difference between Groups PDR and TFA only in the analysis from \#25 to \#35, with 42.88 and $67.34 \%$ of foramen area widening, respectively. Relative to the final foramen shape, $81.7 \%$ were observed to be circular, $17.5 \%$ oval, and $0.8 \%$ flattened.

Conclusion: Our results showed that foramen enlargement allowed an increase in area, maintained the circular shape of the foramen in the majority of cases, irrespective of the system used, and was a feasible option for use during preparation of the root canal system.

Keywords: Apical foramen, Apical foramen enlargement, Endodontics, Root canal therapy, Tooth apices.

The Journal of Contemporary Dental Practice (2021): 10.5005/jp-journals-10024-3234
\end{abstract}

\section{INTRODUCTION}

The primary goal of endodontic therapy is to remove the etiology of the lesion by means of effective chemomechanical cleaning and shaping of the root canal system. ${ }^{1}$ However, more efficient microbial reduction is still a challenge, mainly because of the anatomy of the root canal, especially in the apical area. ${ }^{2}$ Insufficient cleaning, particularly in the apical portion, can cause periapical inflammation. ${ }^{3}$ This could be caused by using instruments with a small tip and/or taper that make it difficult to perform sufficient apical debridement, thereby maintaining contaminated portions. ${ }^{4}$

The instruments with thermal treatment, which are used attached to electrical motors, have several advantages compared with the stainless-steel files previously used because they contribute to the procedures due to their greater flexibility, high cutting efficacy, and improved fracture resistance. Therefore, these instruments provide better maintenance of the root canal morphology, resulting in a more centralized preparation and consequent preservation of the apical foramen. ${ }^{5}$

However, even in the main canal, the instruments have not been able to reach all the walls. ${ }^{2}$ In teeth with chronic periapical lesions, there are microorganisms present in the apical delta, ramifications, dentinal tubules, and cementum. ${ }^{6}$ Large apical preparations increase the chances of the instrument touching a larger percentage of the canal wall surfaces, therefore, being more effective in removing adhering biofilms and infected dentin. Moreover, the larger the preparation, the higher the probability of incorporating anatomic irregularities, fins, and recesses in the final canal shape, ${ }^{4}$ so that the apical widening performed leads to removing a greater number of bacteria and promoting more favorable conditions for healing. ${ }^{7}$

\footnotetext{
1,5School of Dentistry, São Leopoldo Mandic University, Campus Fortaleza, Fortaleza, Ceará, Brazil

${ }^{2}$ School of Dentistry, Paulo Picanço Dental School, Fortaleza, Ceará, Brazil

${ }^{3}$ School of Dentistry, Metropolitan University of Fortaleza, Fortaleza, Ceará, Brazil

${ }^{4}$ School of Dentistry of Sobral, Federal University of Ceará, Campus Sobral, Sobral, Ceará, Brazil

Corresponding Author: Flávia D Vivacqua, School of Dentistry, Metropolitan University of Fortaleza, Fortaleza, Ceará, Brazil, e-mail: fladarius@gmail.com

How to cite this article: Bezerra MM, Feitosa VP, Vivacqua FD, et al. Evaluation of Foraminal Enlargement with Thermally Treated NickelTitanium Systems. J Contemp Dent Pract 2021;22(11):1232-1236.

Source of support: Nil

Conflict of interest: None
}

Hu et al. ${ }^{8}$ observed that instrumentation beyond the limits of the canal can cause foraminal deformations, especially in root canals with curvature. Albuquerque et al. ${ }^{9}$ observed the enlargement of the foramen does not provide more effective cleaning of the apical third, may increase the risk of extravasation of irrigating solutions and filling material, and cause greater apical extrusion. ${ }^{10}$

However, new preparation protocols have been established with new nickel-titanium (NiTi) instruments. ${ }^{4}$ These instruments with thermal treatments have greater flexibility when compared with the conventional alloys, conferring greater centering ability on them during preparation, and less debris extrusion. ${ }^{11}$

() The Author(s). 2021 Open Access This article is distributed under the terms of the Creative Commons Attribution 4.0 International License (https://creativecommons. org/licenses/by-nc/4.0/), which permits unrestricted use, distribution, and non-commercial reproduction in any medium, provided you give appropriate credit to the original author(s) and the source, provide a link to the Creative Commons license, and indicate if changes were made. The Creative Commons Public Domain Dedication waiver (http://creativecommons.org/publicdomain/zero/1.0/) applies to the data made available in this article, unless otherwise stated. 
Reciprocating and Rotatory systems, ProDesign R, and ProDesign Logic (PDR, PDL; Bassi Easy, Belo Horizonte, Minas Gerais, Brazil), respectively, have a controlled memory thermic treatment, as they are manufactured with a NiTi-based shape memory alloy, shaping memory technology (SMT-Wire), like CM wire. ${ }^{12}$ Twisted File Adaptive (TFA; Sybron Endo, Glendora, California, EUA) and WaveOne Gold (WOG; Dentsply-Sirona, Ballaigues, Switzerland) instruments also follow this principle of thermic treatment, with Phase $\mathrm{R}$ and Gold treatments, respectively. ${ }^{13,14}$

The challenge of endodontics is yet to overcome the wide anatomical variability of the root canal system and promote adequate disinfection throughout its extension. However, there is little information available on foraminal enlargement, using NiTi mechanized systems, with regard to foramen morphological alterations. ${ }^{15}$ In this study, the percentage of enlargement and foramen shape was evaluated, when these canals were prepared with rotary or reciprocating systems in maxillary and mandibular molars, in preparations performed $1 \mathrm{~mm}$ beyond the main foramen. The null hypothesis was that there would be no increase in the area of the foramen after widening with different diameters, irrespective of the systems, and that there would be no change in the original foraminal anatomical shapes.

\section{Materials and Methods}

Prior to the study, a 3-sample pilot test was conducted, followed by sample calculation, using BioEstat 5.3 software (BioEstat, Belém, Brazil) and the ANOVA test, using 0.9 power and $p=0.05$. It resulted in 26 canals per group. However, in order to further increase relevance, the sample size was extended to 30 specimens due to the possibility of losses during the mechanical preparation.

Thus, after obtaining approval of the local Ethics Committee, mandibular and maxillary human molars, extracted for other therapeutic reasons, with apical patency and an apical foramen $\leq 200 \mu \mathrm{m}$, complete root formation, similar length (18-21 mm) and curvature angle ranging from $15-35^{\circ}$, were included in this investigation. Teeth that did not fulfill these requirements or that showed any sign of root resorption were substituted. The specimens selected were separated into batches by similar characteristics and then randomly divided into four groups of 30 canals each.

The access cavity was performed using diamond drills \#1012 and \#3081 (KG Sorensen, Cotia, Sao Paulo, Brazil) under high speed and irrigation. C-Pilot \#15 file (VDW GmbH, Munich, Germany) was inserted into the canals until the tip could be seen through the apical foramen (AF) at 40× magnification of a clinical microscope (Alliance, São Carlos, Sao Paulo, Brazil), and the working length (CT) was established by adding $1 \mathrm{~mm}$ beyond the AF.

The specimen crowns were embedded in condensation silicon (Yller Biomateriais SA, Pelotas, Rio Grande do Sul, Brazil) dispensed on standardized plastic supports, which served as a template to keep the apexes facing upwards. This was achieved with the use of a 2.0MP 800 $\times$ HD USB Digital Microscope (Jinjiang Jiaxing Group Co., Ltd., Xiamen, Fujian, China), which captured both preand postoperative foramen images at $400 \times$ magnification. For standardization of later images, a school ruler was used to maintain the same focal length throughout the study. Three images of each specimen were captured with a digital pachymeter (Mitutoyo, Suzano, Sao Paulo, Brazil) for calibration, at each time.

\section{Root Canal Preparation}

The four groups were instrumented with the use of the following instruments at all times: A Glidepath file, a shaping file and a foraminal enlargement file, in the Groups as follows: PDL Group ( $n=30$ ): PDL 25/0.01; PDL 25/0.06 and PDL 35/0.05; PDR Group $(n=30)$ : PDS $25 / 0.01$ (ProDesign S), PDR 25/0.06 and PDR 35/0.05; TFA Group $(n=30)$ TFA 20/0.04; TFA 25/0.06 and TFA 35/0.04; WOG Group ( $n=30$ ): ProGlider (16/0.02), WOG 25/0.07, and WOG 35/0.06.

Group PDL was prepared using the VDW Silver endodontic motor (VDW GbmH), operating at 500 RPM (cervical and middle thirds), 350 RPM (apical third), and $200 \mathrm{~g} \mathrm{~cm}$. For the PDR and WOG groups, VDW Silver was used in the reciprocating WaveOne function. In the TFA Group, the Elements motor (Axis/SybronEndo, Orange, California, USA) was used, configured in the TF Adaptive function. The glidepath files ProDesign S 25/0.01 and ProGlider 16/0.02 were suggested in the protocols of their respective Manufacturers, and were used for preparations at 350 RPM and $100 \mathrm{~g} \mathrm{~cm}$.

After preparation, the teeth were reassembled in the condensation silicone mold, adjusted to the same device, to obtain identical positions to those in the original images. Magnified images of files \#25 and \#35 were obtained. The initial image was named IN; the intermediate, after shaping file \#25, was named \#25; and the final was named \#35.

\section{Image Analysis}

In all images, the foraminal margin was demarcated. Thus, the horizontal, vertical, and AF area dimensions were obtained using the ImageJ software (Wayne Rasband of the Research Services Branch, National Institute of Mental Health, Bethesda, USA). These measurements were performed in triplicate by a blind researcher, and mean of the values found was calculated.

To determine the intragroup foraminal enlargement, the area of enlargement was compared in each phase. To determine the intergroup foraminal enlargement, the percentage of enlargement was compared, considering the pre- and postinstrumentation images in each phase. To determine the foramen shape, the difference between the horizontal and vertical linear diameters was compared. Based on the concepts of plane geometry ${ }^{16}$ that for the oval shape, there is a difference of $30 \%$ between its height and width dimensions; the foramens were classified as being circular, when this difference was up to $20 \%$; ovals, when this difference was between 20 and 40\%; and flattened when this difference was higher than $40 \%$ (Fig. 1).

\section{Statistical Methods}

The data presented a nonparametric distribution. The analyses were made by the Friedman test, in the intragroup comparison; by Kruskal-Wallis test, in the intergroup comparison; and by Chi-square test, in the shape comparison. The level of statistical significance was set at $p<0.05$.

\section{Results}

\section{Percentage of Foraminal Area Enlargement in the Intra- and Intergroup Systems}

The median and range values of the percentage, of foraminal enlargement produced by the instrumentation techniques, are presented in Table 1. The results showed that within the same group, there was a statistical difference between the images IN-\#25; \#25-\#35, and IN-\#35 ( $p<0.05)$. Considering the percentage of enlargement in the foraminal area, between the four systems, there was no statistical difference between the images IN-\#25 and IN-\#35 ( $p>0.05)$; however, there was statistical difference between the images \#25-\#35, but only in Groups PDR and TFA ( $p<0.05)$. 

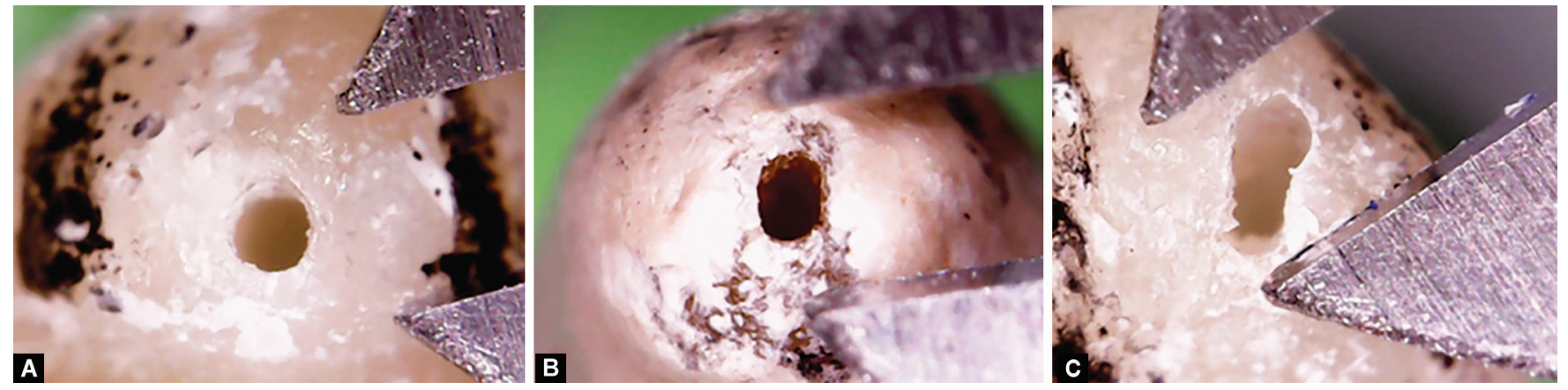

Figs $1 \mathrm{~A}$ to C: Present post-preparation foraminal aspects produced and illustrate the classification performed: (A) Circular; (B) Oval; (C) Flattened

Table 1: Median of the foramen enlargement, in each phase $(n=30)$

\begin{tabular}{|c|c|c|c|c|c|c|c|c|c|c|c|c|c|}
\hline \multirow[b]{2}{*}{ Phase } & \multicolumn{3}{|c|}{$P D L$} & \multicolumn{3}{|c|}{$P D R$} & \multicolumn{3}{|c|}{ TFA } & \multicolumn{3}{|c|}{ WOG } & \multirow[b]{2}{*}{$p$} \\
\hline & Median & Min. & $\overline{\text { Max. }}$ & Median & Min. & Max. & Median & Min. & $\overline{\operatorname{Max}}$ & Median & Min. & $\overline{\operatorname{Max}}$ & \\
\hline IN-25 & $73.8 \%^{\mathrm{A}, \mathrm{a}}$ & 17.0 & 503.6 & $95.7 \%^{\mathrm{A}, \mathrm{a}}$ & 23.7 & 308.7 & $78.4 \%^{\mathrm{A}, \mathrm{a}}$ & 10.8 & 288.0 & $81.6 \%^{A, a}$ & 24.71 & 284.9 & $>0.05$ \\
\hline $25-35$ & $54.1 \%^{\mathrm{B}, \mathrm{ab}}$ & 11.5 & 316.4 & $42.9 \%^{\mathrm{B}, \mathrm{b}}$ & 3.9 & 112.77 & $67.3 \%{ }^{\mathrm{B}, \mathrm{a}}$ & 19.6 & 354.6 & $50.6 \%^{\mathrm{B}, \mathrm{ab}}$ & 7.41 & 118.9 & $<0.05$ \\
\hline IN-35 & $193.3 \% \%^{\mathrm{C}, \mathrm{a}}$ & 38.1 & 602.9 & $208.9 \%^{\mathrm{C}, \mathrm{a}}$ & 57.1 & 514.29 & $232.9 \%^{\mathrm{C}, \mathrm{a}}$ & 66.2 & 669.2 & $200.4 \%^{\mathrm{C}, \mathrm{a}}$ & 39.76 & 426.8 & $>0.05$ \\
\hline$p$ & $<0.05$ & & & $<0.05$ & & & $<0.05$ & & & $<0.05$ & & & \\
\hline
\end{tabular}

In column, intragroup comparisons. Different capital letters indicate statistical significant differences. Intergroup comparisons, in row. Different lower case letters present statistical significant

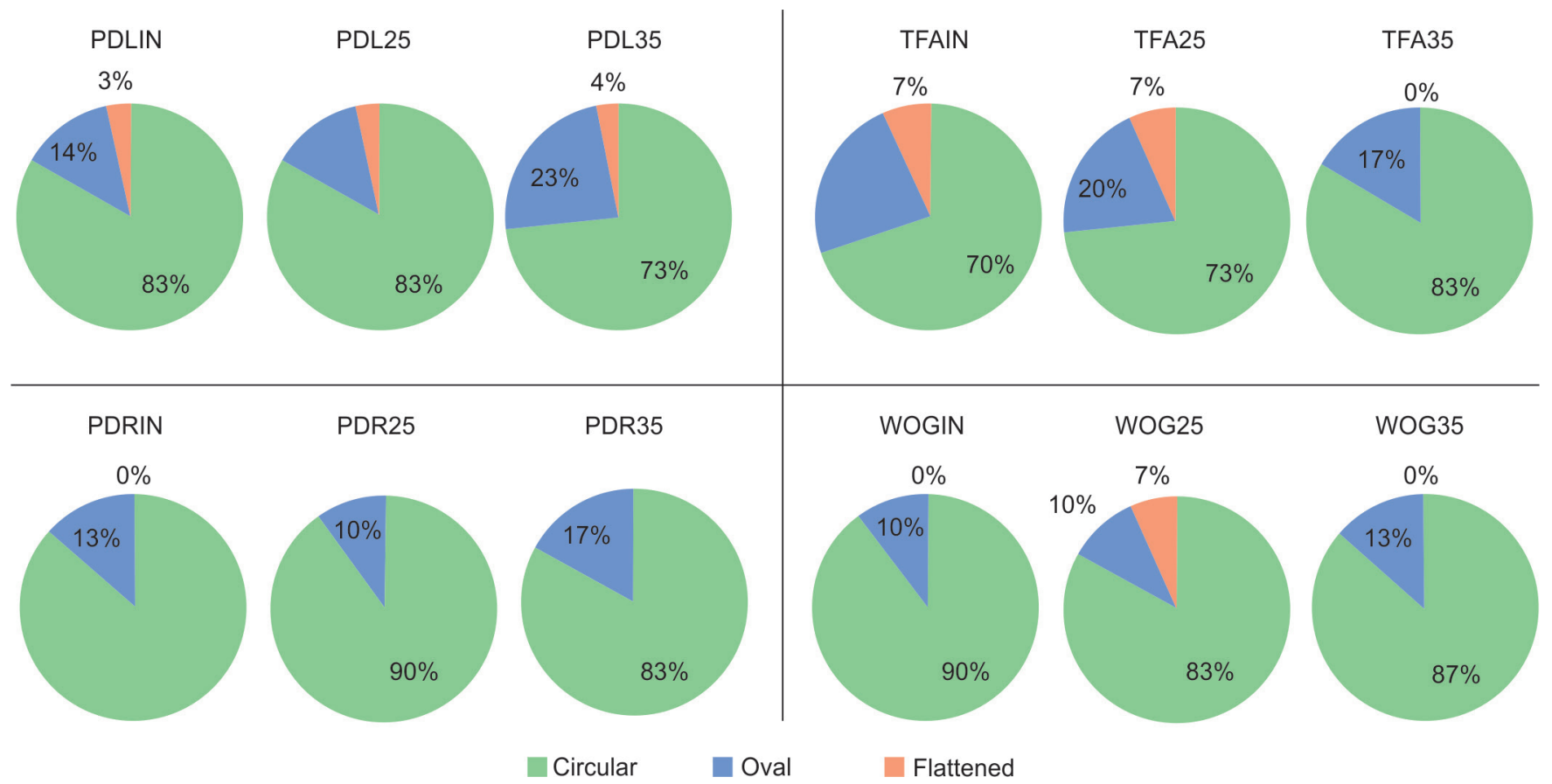

Fig. 2: Frequency percentage values for each group, of the foraminal shapes for its respective instruments (IN, \#25 and \#35)

\section{Analysis of the Foraminal Shape after Each Phase, between the Systems}

After instrumentation with file \#25, only $13.1 \%$ of the shapes that were circular were observed to become oval, and $4 \%$ resulted in becoming flattened intermediate shapes. Regarding the passage of the \#35 file, a single case (0.8\%) belonging to the PDL group, which was circular in phases IN and \#25, was observed to have become flattened. Of the 120 canals analyzed, in only 21 (17.5\%) of them, the final format was classified as being oval, with their initial and \#25 formats varying between circular, oval, or flattened shapes. There were no statistical differences between the groups $(p>0.05)$ (Fig. 2).

\section{Discussion}

The null hypothesis was rejected since there were differences between all the phases within the same system, and differences 
were also detected in the percentages of enlargement achieved between some of the groups. However, there were no differences between foramen shapes in all four groups.

At present, a single reference to the foraminal shape was found in the literature, concerning an instrument made with SMT-Wire, used in preparations beyond the $A F^{10}$ Thus, in the present study, the percentage of foramen enlargement and classification of the shapes of AFs were determined. In order to approximate the study conditions to the clinical reality, without risking the homogeneity of the sample, mesial canals of mandibular molars and vestibular canals of maxillary molars were used. The samples selected had moderate curvatures, AFs, and diameters smaller than $200 \mu \mathrm{m}$, according to Vivacqua et al. ${ }^{17}$

In the literature, observation of shape of AFs by recording their format in photographic documentation has also been used by several authors. ${ }^{10,18,19}$ However, the classifications were used with predefined values. In the present study, we used a percentage basis, because of the three different foramen diameters analyzed.

For improved understanding of the changes in shape of the apical foramen, our study included the concepts of apical patency ${ }^{7}$ and foraminal enlargement, ${ }^{20,21}$ which according to Souza, ${ }^{8}$ causes a significant reduction in bacteria in the apical third, preventing the accumulation of pulp and dentin debris capable of causing loss of patency, transportations, and perforations.

Studies in dogs have shown that $1 \mathrm{~mm}$ instrumentation beyond foramen does not hinder the repair process. ${ }^{20-22}$ Paredes-Vieyra and Enriquez ${ }^{23}$ reported that enlarged apical instrumentation could lead to better healing in cases of apical periodontitis, with no correlation between foramen enlargement and increased incidence of pain. ${ }^{24}$ However, according ElAyouti et al., ${ }^{25}$ apical enlargement causes unnecessary dentin removal and does not provide any additional benefit during endodontic treatment.

The literature has indicated that larger apical diameters should be recommended ${ }^{26}$ with evidence indicating a more efficient irrigation of the apical region, ${ }^{27,28}$ better infection control, and overall filling quality. ${ }^{29}$ However, when excessively performed, especially in molars, this can result in undesirable side effects. ${ }^{25}$ In our study, the final apical enlargement was performed with the \#35 file used $1 \mathrm{~mm}$ beyond the foramen, corroborating the study by Sant'Anna Júnior et al., ${ }^{30}$ in which preparation of the canals was performed with the \#40 file, significantly dilating the volume in the apical third, but without any excessive dentin removal.

In this study, the evaluation showed that the rotary and reciprocating file systems use achieved the enlargement of the foramen area, when the initial (IN) and postinstrumentation areas (\#35) were compared. Whereas within the same system, there was a statistically significant difference. However, in the comparison of the percentage enlargement values between the systems, and in each enlargement diameter, statistical difference was only observed between Groups PDR and TFA, and between the images \#25 and \#35.

González Sánchez et al., ${ }^{19}$ who evaluated apical transportation in curved canals when NiTi rotary instruments were used, showed that there was foraminal deformation, in comparisons with the initial images. Silva Santos et al. ${ }^{31}$ found the same result ${ }^{31}$ of deformation, irrespective of the kinematics used. In our study $81.7 \%$ of the cases were observed as being circular, $17.5 \%$ with oval shapes, and $0.8 \%$ with flattened foramen shapes after instrumentation with \#35 instruments; with their initial and intermediate shapes varying between circular, oval, or flattened shapes, therefore, not corroborating the findings of the above-mentioned authors.
As has been pointed out by other previous studies, small and flattened canals were changed into rounder and more smoothly tapered canals, irrespective of the technique or system used during the preparation. ${ }^{3,4,32}$ Filizola et al. ${ }^{33}$ believed that geometric changes could be different every third, suggesting the importance of evaluating parameters such as area and perimeter, as was done in our study.

According to Burklein et al., ${ }^{34}$ rotary and reciprocating instruments appear to be capable of maintaining the canal curvature, which corroborated the findings of the present study, in which instrumentation beyond the apex did not affect foraminal morphology. In a similar manner, Filizola et al. ${ }^{33}$ concluded that irrespective of the number of instruments, kinematics, or heat treatment of alloys, the systems evaluated did not cause dimensional changes or transportation in critical apical area. However, we only included roots with curvatures up to $35^{\circ}$; therefore, more caution will be needed to extrapolate these results to more severe curvatures. Vivacqua et al. ${ }^{35}$ analyzing the cervical and the apical third relative to deviation and transportation of canals found no statistical difference when three working lengths and three final apical enlargements were considered: PDL 25.06/+1 mm, PDL 35.05/ foramen, and PDL 50.01/-1 mm.

Our results suggested that instrumentation $1 \mathrm{~mm}$ beyond the apex did not promote foraminal deformations, and that the use of apical patency and foramen enlargement may become an alternative for endodontic preparation, but with the use of appropriate techniques and instruments. The results of an ex-vivo study must be carefully evaluated before being considered clinically.

\section{Conclusion}

Under the conditions tested, it could be concluded that foraminal enlargement allowed an increase in the foraminal area in all Groups, with maintenance of the circular foramen shape in the majority of cases, irrespective of the sequence of files used. Moreover, it could be inferred that the introduction of heat-treated $\mathrm{NiTi}$ alloy instruments could be an option for preparations beyond the foraminal level, considering the need to expand the AF as a way to achieve a more efficient and safe decontamination in this region.

\section{Clinical Relevance of this Article}

The greater enlargement of root canals apical portion, as well as the major foramen, has been recommended, in literature, to achieve a better disinfection. Choosing the instruments correctly will avoid accidents, as deformations, and guarantee a better chance of success.

\section{References}

1. Butcher S, Mansour A, Ibrahim M. Influence of apical preparation size on effective conventional irrigation in the apical third: a scanning electron microscopic study. Eur Endod J 2019;4(1):9-14. DOI: 10.14744/ eej.2018.

2. Vieira ML, Dantas HV, Sousa FB, et al. Morphologic changes of apical foramen and microcrack formation after foraminal enlargement: a scanning electron microscopic and micro-computed tomographic analysis. J Endod 2020;46:17. DOI: 10.1016/j.joen.2020.07.017.

3. Nair PN, HenryS, Cano V. Microbial status of apical root canal system of human mandibular first molars with primary apical periodontitis after "one visit" endodontic treatment. Oral Surg Oral Med Oral Pathol Oral Radiol Endod 2005;99(2):231-252. DOI: 10.1016/j.tripleo.2004.10.005. 
4. Wu MK, R'oris A, Barkis D, et al. Prevalence and extent of long oval canals in the apical third. Oral Surg Oral Med Oral Pathol Oral Radiol Endod 2000;89(6):739-743. DOI: 10.1067/moe.2000.106344.

5. Pereira ES, Viana AC, Buono VT, et al. Behavior of nickel-titanium instruments manufactured with different thermal treatments. J Endod 2015;41:67-71. DOI: 10.1016/j.joen.2014.06.005.

6. Rodrigues RCV, Zandi H, Kristoffersen AK, et al. Influence of the apical preparation size and the irrigant type on bacterial reduction in root canal-treated teeth with apical periodontitis. J Endod 2017;43(7):1058-1063. DOI: 10.1016/j.joen.2017.02.004.

7. Yadav SS, Shah N, Logani A, et al. Effect of "apical clearing" and "apical foramen widening" on apical ramifications and bacterial load in root canals: an ex-vivo stereomicroscopic study. Bull Tokyo Dent Coll 2014;55(2):67-75. DOI: 10.2209/tdcpublication.55.67.

8. Hu W, Whitten B, Sedgley C, et al. Effect of three NiTi files on transportation of the apical foramen. Int Endod J 2014;47:1064-1071. DOI: 10.1111/iej.12249.

9. Albuquerque PP, Duarte MA, Pelegrine RA, et al. Influence of foraminal enlargement on the apical extrusion of filling material: volumetric analysis using micro-computed tomography. Aust Endod J 2020;46:210-216. DOI: 10.1111/aej.12394.

10. Frota MMA, Bernardes RA, Vivan RR, et al. Debris extrusion and foraminal deformation produced by reciprocating instruments made of thermally treated NiTi wires. J Appl Oral Sci 2017;26:1-8. DOI: 10.1590/1678-7757-2017-0215.

11. Shen Y, Zhou HM, Zheng YF, et al. Current challenges and concepts of the thermomechanical treatment of nickel-titanium instruments. J Endod 2013;39(2):163-172. DOI: 10.1016/j.joen.2012.11.005.

12. Rodrigues $C T$, Duarte MAH, De Almeida MM, et al. Efficacy of $\mathrm{CM}$-wire, M-wire, and Nickel-Titanium instruments for removing filling material from curved root canals: a micro-computed tomography study. J Endod 2016;42(11):1651-1655. DOI: 10.1016/ j.joen.2016.08.012.

13. Gergi R, Arbab-Chirani R, Osta N, et al. Micro-computed tomographic evaluation of canal transportation instrumented by different kinematics rotary nickel titanium instruments. J Endod 2014;40(8):1223-1227. DOI: 10.1016/j.joen.2014.01.039.

14. Webber J. Shaping canals with confidence: WaveOne GOLD singlefile. Int Dent 2016;6(3):6-17.

15. Olivier JG, Garcia-Font M, Gonzalez-Sanchez JA, et al. Danger zone analysis using cone beam computed tomography after apical enlargement with K3 and K3XF in a manikin model. J Clin Exp Dent 2016;8(4):361-367. DOI: 10.4317/jced.52523.

16. Simmons GF. Calculus with analytic geometry. 2nd ed. New York: McGraw-Hill Education; 1995.

17. Vivacqua FD, Canto M, Candeiro GT, et al. Durability of two R-phase rotary systems used in the mechanical instrumentation of dilacerated root canals. J Contemp Dent Pract 2019;20(4):1-4. DOI: 10.5005/ jp-journals-10024-2530.

18. Marroquín BB, El-Sayed MA, Willershausen-Zönnchen B. Morphology of the physiological foramen: I. Maxillary and mandibular molars. J Endod 2004;30(5):321-328. DOI: 10.1097/00004770-20040500000005.

19. González Sánchez JA, Duran-Sindreu F, de Noe S, et al. Centring ability and apical transportation after overinstrumentation with ProTaper Universal and ProFile Vortex instruments. Int Endod J 2012;45(6):542-551. DOI: 10.1111/j.1365-2591.2011.02008.

20. Benatti O, Valdrigh L, Biral RR, et al. A histological study of the effect of diameter enlargement of the apical portion of the root canal. J Endod 1985;11(10):428-434. DOI: 10.1016/S00992399(85)80080-7.
21. De Souza Filho FJ, Benatti O, de Almeida OP. Influence of the enlargement of the apical foramen in periapical repair of contaminated teeth of dog. Oral Surg Oral Med Oral Pathol 1987;64(4):480-484. DOI: 10.1016/0030-4220(87)90157-5.

22. Borlina SC, De Souza V, Holland R, et al. Influence of apical foramen widening and sealer on the healing of chronic periapical lesions induced in dog's teeth. Oral Surg Oral Med Oral Pathol Oral Radiol Endod 2010;109(6):932-940. DOI: 10.1016/j.tripleo.2010.01.028.

23. Paredes-Vieyra J, Enriquez FJ. Success rate of single versus two-visit root canal treatment of teeth with apical periodontitis: a randomized controlled trial. J Endod 2012;38(9):1164-1169. DOI: 10.1016/ j.joen.2012.05.021.

24. Arias A, Azabal M, Hidalgo JJ, et al. Relationship between postendodontic pain, tooth diagnostic factors, and apical patency. J Endod 2009;35(2):189-192. DOI: 10.1016/j.joen.2008.11.014.

25. ElAyouti A, Dima E, Judenhofer MS, et al. Increased apical enlargement contributes to excessive dentin removal in curved root canals: a stepwise microcomputed tomography study. J Endod 2011;37(11):1580-1584. DOI: 10.1016/j.joen.2011.08.019.

26. Pérez AR, Alves FR, Marcelino-Alves MF, et al. Effects of increased apical enlargement on the amount of unprepared areas and coronal dentine removal: a micro-computed tomography study. Int Endod J 2018;51(6):684-690. DOI: 10.1111/iej.12873.

27. Brunson M, Heilborn C, Johnson DJ, et al. Effect of apical preparation size and preparation taper on irrigant volume delivered by using negative pressure irrigation system. J Endod 2010;36(4):721-723. DOI: 10.1016/j.joen.2009.11.028.

28. Srikanth P, Krishna AG, Srinivas S, et al. Minimal apical enlargement for penetration of irrigants to the apical third of root canal system: a scanning electron microscope study. J Int Oral Health 2015;7(6):92-96. PMID: 26124608

29. ElAyouti A, Kiefner P, Hecker $\mathrm{H}$, et al. Homogeneity and adaptation of endodontic fillings in root canals with enlarged apical preparation. Oral Surg Oral Med Oral Pathol Oral Radiol Endod 2009;108(3): 141-146. DOI: 10.1016/j.tripleo.2009.04.022.

30. Sant'Anna Júnior A, Cavenago, BC, Ordinola-Zapata R, et al. The effect of larger apical preparations in the danger zone of lower molars prepared using the Mtwo and Reciproc systems. J Endod 2014;40(11):1855-1859. DOI: 10.1016/j.joen.2014.06.020.

31. Silva Santos AM, Portela FMSF, Coelho MS, et al. Foraminal deformation after foraminal enlargement with rotary and reciprocating kinematics: a scanning electronic microscopy study. J Endod 2018;44(1):145-148. DOI: 10.1016/j.joen.2017.08.013.

32. Arias $A$, Paqué $F$, Shyn $S$, et al. Effect of canal preparation with TRUShape and Vortex rotary instruments on three-dimensional geometry of oval root canals. Aust Endod J 2018;44(1):32-39. DOI: 10.1111/aej.12201.

33. Filizola de Oliveira DJ, Leoni GB, Goulart RS, et al. Changes in geometry and transportation of root canals with severe curvature prepared by different heat treated nickel-titanium instruments: a micro-computed tomographic study. J Endod 2019;45(6):768-773. DOI: 10.1016/j.joen.2019.02.018.

34. Burklein S, Hinschitza K, Dammaschke T, et al. Shaping ability and cleaning effectiveness of two single-file systems in severely curved root canals of extracted teeth: Reciproc and WaveOne versus Mtwo and ProTaper. Int Endod J 2012;45(5):449-461. DOI: 10.1111/ j.1365-2591.2011.01996.

35. Vivacqua FD, Duarte MAH, Vivan RR, et al. Analysis of instrumentation protocols regarding the quality of mesial canal preparation in mandibular molars: a micro-computed tomographic study. J Endod 2021;1-6. DOI: 10.1016/j. joen.2021.06.008. 